\title{
Understanding Representation: Contrasting Gesture and Sketching in Design Through Dual-Process Theory
}

Philip Cash ${ }^{1 *}$, Anja Maier ${ }^{1}$

Please cite as: Cash, P., Maier, A. (2021). Understanding Representation: Contrasting Gesture and Sketching in Design Through Dual-Process Theory. Design Studies, 73(March), pages: 100992.

DOI: 10.1016/j.destud.2021.100992

\section{Affiliation:}

1 Technical University of Denmark, Denmark

*Corresponding author

\section{Highlights}

> A multi-experiment study of gesture and sketching across design tasks.

$>$ A novel dual-process theory explanation of design representation.

$>$ Identification of match between representation at input and response as a key factor.

$>$ Suggested resolutions to previously contradictory findings.

$>$ Implications for when and where to use different design representation modes. 


\title{
Understanding Representation: Contrasting Gesture and Sketching in Design Through Dual-Process Theory
}

\begin{abstract}
Representation is essential to design work. While there is a multitude of research on, for example, gesture, prototyping, and sketching, there is a critical need for a more general account of design representation, able to explain diverse results across representation modes and design tasks. We address this need by experimentally testing dual-process theory hypotheses regarding the impact of gesture and sketching on a range of design tasks, including reproduction, evaluation, elaboration, ideation, and selection. Central to this is the (mis)match between representation mode at input/response, and the interaction between Type 1 and Type 2 processing. These findings support a novel dual-process explanation of design representation, suggest resolutions to previously contradictory findings, and provide implications for design theory, education, and practice.
\end{abstract}

Keywords: design cognition; conceptual design; reasoning; communication; design representation

Representation is an essential aspect of design work (Luck, 2014; Oxman, 1997) and plays a central role in design communication, evaluation, conceptualisation, and cognition (Eris, Martelaro, \& Badke-Schaub, 2014; Scaife \& Rogers, 1996; Visser \& Maher, 2011). While representation ranges from writing to 3D mock-ups (Pei, Campbell, \& Evans, 2011), two major modes used during conversation are gesture and sketching (Cash \& Maier, 2016; Kavakli \& Gero, 2001). Research on sketching has been translated into numerous communication and design tools (Kulkarni, Summers, Vargas-Hernandez, \& Shah, 2000), as well as specific design education (Booth, Taborda, Ramani, \& Reid, 2016). However, while it is acknowledged that gesture is distinct from sketching (Cash \& Maier, 2016), the differing impact of these representation modes on design work remains critically understudied (Babapour, 2016; Harkki, Seitamaa-Hakkarainen, \& Hakkarainen, 2018). This deficit prevents efforts to develop theory-driven design support and education able to effectively take advantage of each representation mode's unique properties.

In order to address this deficit a more general understanding of design representation is needed. Here, generality has two dimensions: across representation modes, and across design tasks. Prior representation research has typically focused on these dimensions in isolation. For example, Goldschmidt (2007) and Van 
Der Lugt (2005) examine a single mode across design tasks, while Linsey et al. (2011) and Eris et al. (2014) examine multiple modes in specific tasks. Despite this, numerous authors highlight the potential for developing more general explanative and predictive power through the operationalisation of cognitive theory (Badke-Schaub \& Eris, 2014; Cash, Daalhuizen, Valgeirsdottir, \& Van Oorschot, 2019; Crilly \& Cardoso, 2017). Thus, we aim to provide a more general account of design representation by operationalising and testing predictions grounded in generic cognitive theory.

To address this aim we test predictions derived from dual-process theory (Evans, 2008) regarding the impact of gesture and sketching on multiple design tasks, in theory testing mode (Cash, 2018). We do this via three, multi-part experimental studies testing hypotheses regarding reproduction, evaluation, elaboration, ideation, and selection. Based on this we contribute a novel, processing-based explanation of gesture and sketching in design, extending current theory in the areas of design representation and design cognition.

\section{$1 \quad$ Gesture and sketching in design}

Significant research has focused on representation and its varied roles in design (Becvar, Hollan, \& Hutchins, 2008; Luck, 2010). This has delivered insight into a wide array of representational phenomena, such as reflective sketching (Menezes \& Lawson, 2006; Scrivener, Ball, \& Tseng, 2000), gestural computer interaction (Waldherr, Romero, \& Thrun, 2000), and multi-modal communication (Murphy, 2005). Further, research on sketching and other representation modes has formed the basis for a wide array of mode-specific tools, guides, and educational supports (Booth et al., 2016; Kulkarni et al., 2000). Research on representation is thus relevant to almost all aspects of design work.

There are numerous studies of visualisation and prototyping (Babapour, 2016; Pei et al., 2011) as well as more abstract explanations of how representations provide external support for cognition (Scaife \& Rogers, 1996; Tversky, 2011) and facilitate the resolution of uncertainty (Ball \& Christensen, 2019; Cash \& Kreye, 2017). However, a major question remains regarding how these insights can be synthesised. Specifically, there are few comparative studies in this area (Maier \& Kleinsmann, 2013; Toh \& Miller, 2014; Visser \& Maher, 2011). Therefore, there is a need for both theoretical and empirical synthesis.

Establishing a common theoretical foundation for understanding design representation could provide the basis for generalising insights across contexts (Cash, 2018; Wacker, 2008), as well as to new modes or tasks emerging in design practice (Bilda \& Demirkan, 2003; Jonson, 2005). Given the widely acknowledged link between representation and cognition (Cash \& Kreye, 2017; Scaife \& Rogers, 1996; Wilson, 2002), there is a potential opportunity for obtaining such a foundation through cognitive theory. Specifically, prior design research describes various perspectives on representation related information processing, mental simulation, and reflection, which are all linked to dual-process theory (Stanovich, West, \& Toplak, 2012). 
Following recent discussions of future directions in design cognition (Badke-Schaub \& Eris, 2014; Cash, Daalhuizen, et al., 2019) and uncertainty (Ball \& Christensen, 2019; Cash \& Kreye, 2017), as well as applied studies of creativity (Beaty et al., 2018; Kleinmintz, Ivancovsky, \& Shamay-Tsoory, 2019) and design methodology (Daalhuizen, 2014), we come to a focus on dual-process theory (Evans \& Stanovich, 2013; Stanovich, 2009). While dual-process theory is broadly accepted in cognitive psychology it is yet to be widely operationalised in design research (Crilly \& Cardoso, 2017; Kannengiesser \& Gero, 2019). Therefore, before further design specific theory construction is possible it is first necessary to test basic dual-process explanations in the design context (Cash, 2018; Wacker, 2008).

The premise of dual-process theory is that there are at least two major types of cognitive processing: Type 1 that is intuitive and fast; and Type 2 that is analytical, deliberate, and slow (Evans \& Stanovich, 2013). While Type 1 deals with intuitive associations, judgements, and rapid responses, Type 2 deals with deliberate analysis, mental simulation ${ }^{1}$, and reflection (Stanovich, 2009). Typically, designers move between intuitive and reflective periods as they develop and define concepts (Steinert \& Leifer, 2011; Wiltschnig, Christensen, \& Ball, 2013); and most design tasks appear to build on some interaction between both postulated types of processing (Badke-Schaub \& Eris, 2014). For example, ideation is characterised by bursts of rapid, associative idea generation (linking to accounts of Type 1 processing), interspersed with deliberate, reflective periods of idea interpretation and reorientation (linking to accounts of Type 1 processing) (Gonçalves, Cardoso, \& Badke-Schaub, 2016; Hay et al., 2017). As such, ideation can be described in terms of Type 1 and Type 2 processing interacting across the duration of the task. Similar accounts can be derived for design elaboration and selection, where rapid, associative thinking is used to explore the identified problem or solution space, while deliberate reflective thinking is used to re-frame, re-contextualise, or re-direct the process (BadkeSchaub \& Eris, 2014; Hay et al., 2017; Sevier et al., 2017). This is reinforced by design training and methods that typically seek to combine both types of processing, for example, Brainwriting directs intuitive idea generation followed by reflective idea clustering and evaluation. As such, while individual types of processing are likely to be dominant during specific periods of a design task, they can be considered as acting in conjunction across the task as a whole. Therefore, dual-process theory has the potential to develop generic explanations of complex differences in response to various design representation inputs (in this case gestured and sketched), across design tasks. Specifically, we operationalise and test dual-process hypotheses across tasks ranging from generative to evaluative, including reproduction, evaluation, elaboration, ideation, and selection.

\footnotetext{
${ }^{1}$ We use 'mental simulation' throughout in order to distinguish this from physical or other types of simulation commonly found in design.
} 
Following dual-process theory, two basic mechanisms underpin the logic for the tested hypotheses and the differentiation of responses to various representational inputs. These are detailed in the following sections and summarised in Figure 1 with respect to a basic dual-process model derived from Stanovich, West and Toplak (2012), following Daalhuizen (2014). Importantly, these constitute postulates based on explanations of dual-process theory; but are yet to be definitively proven. As such, they form an explanative basis for this work, but remain to be tested. In Figure 1, we highlight the generic variables at play, i.e. the mode and information content of the input coupled with the mode of the desired response.

- Mechanism 1: When the representation mode of an input and response are mismatched, i.e. sketched input and gestured output or vice versa, Type 2 processing is required to interpret and manipulate the input (Evans \& Stanovich, 2013). For example, via mental simulation and reflective decoupling (Ball \& Christensen, 2009; Stanovich, Toplak, \& West, 2008). In contrast, matched input/response could support simple associations and default to Type 1 processing (Stanovich et al., 2008). This will be particularly evident in reproduction, generative elaboration, and ideation tasks (see Hypotheses 1A-F).

- Mechanism 2: The representation mode of an input will implicitly emphasise certain aspects of its information content, which we refer to as 'implicit modal information', shaping Type 1 intuitive processing (Evans \& Stanovich, 2013). For example, by prompting implicit associations (Stanovich et al., 2008). Therefore, responses will emphasise the implicit information associated with a representation mode, e.g. the 3D spatial and dynamic aspects of gestures. This will be distinct from the input's explicit information content and be particularly evident in reproduction, generative elaboration, and ideation tasks (see Hypotheses 2A-E).

Each of the following sections elaborates these mechanisms into hypotheses, based on the model in Figure 1 and the proposed explanations of Stanovich, West and Toplak (2012).

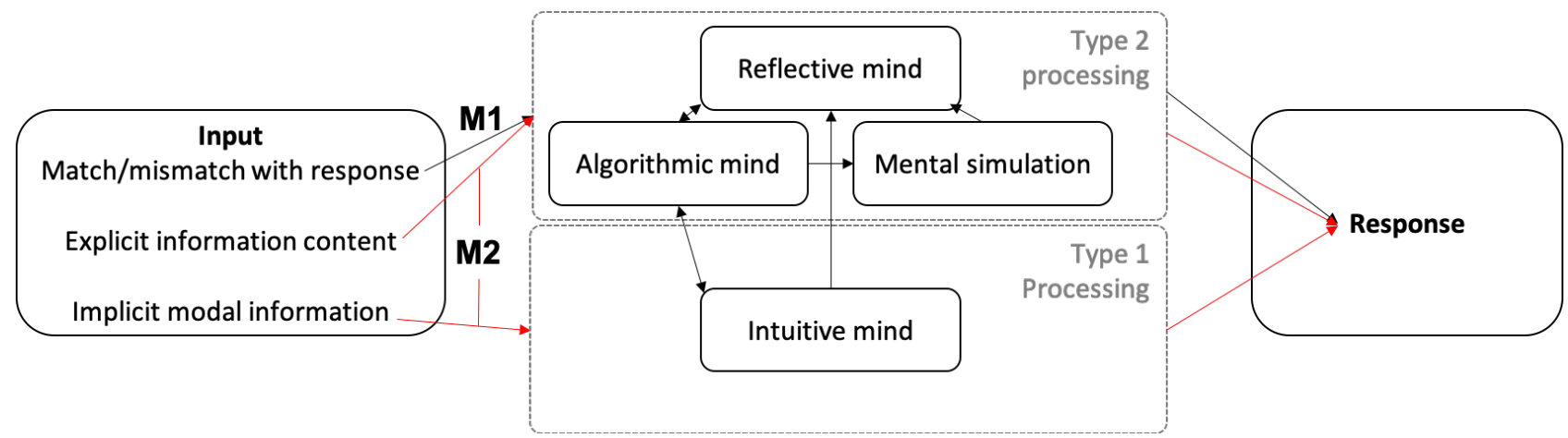

Figure 1: Theoretical model illustrating hypotheses linking differences in inputs to potential differences in processing and subsequent design responses

\subsection{Varying mental simulation and reflective processing demands}


When the representation mode at input and response are mismatched (e.g. gestured input and sketched response) there is an increased demand on Type 2 processing, as mental simulation and reflection are required to decouple and reformulated the input into a different response. In contrast, when input and response are matched (e.g. sketched input and response) it is possible to recite inputs via simple associations and default Type 1 processing (Hegarty, 2004; Stanovich et al., 2008). Critically, Type 2 processing, and mental simulation in particular, is essential to interpretation. For example, it can explain how designers identify nonvisual functions or other insights from sketches (Baskinger \& Nam, 2006; Suwa \& Tversky, 1997). Type 2 processing increases the amount of time and effort needed to interpret and respond to inputs (Norman et al., 2017; Stanovich et al., 2008) and can potentially lead to greater variation in interpretation (Stacey, Eckert, \& McFadzean, 1999). Designers are continuously asked to deal with matched/mismatched input/response representations. For example, during detailed design it is common to present concept drawings that design team members need to accurately reproduce and annotate in their own logbooks (McAlpine, Cash, \& Hicks, 2017). Similarly, during creative sessions it is common to show sketches or other visualisations that prompt designers to gesture, sketch, or verbalise ideas (Linsey et al., 2011). Hence, these effects can be connected to design relevant measures including, reproduction success, accuracy of reproduction, and degree of elaboration. In the context of this research, gestured verses sketched inputs will be distinguished based on their match/mismatch with the sketched response (used to allow for comparison with prior design studies (Linsey et al., 2011; Sevier et al., 2017)). This leads to three reproduction and elaboration related hypotheses:

Reproduction: Matched input/response will lead to better reproduction measured via: H1A overall success rate; $\mathrm{H} 1 \mathrm{~B}$ number of reproduced i) parts and ii) movements.

Elaboration: Matched input/response will lead to more elaboration, measured via: H1C number of i) functions, ii) parts, and iii) features developed during elaboration.

The increased Type 2 processing demands introduced by mismatched input/response specifically require mental simulation and reflection (Stanovich et al., 2012). This has been shown to support greater adaption to task and generative performance (Furlan, Agnoli, \& Reyna, 2016; Norman et al., 2017). Hence, this can again be connected to design relevant measures in terms of accuracy of reproduction and degree of elaboration. This connects to notions of reflection in action during design (Valkenburg \& Dorst, 1998). Thus, we can define two hypotheses associated with reproduction and elaboration:

Reproduction: Matched input/response will lead to lower variation in reproduction, measured via: H1D deviance from input in terms of i) number of parts and ii) movements, iii) topology, and iv) mode of action.

Elaboration: Matched input/response will lead to lower quality elaboration, measured via: H1E i) overall quality and ii) increased originality and development from the input. 
Finally, increased mental simulation could correspond to increased cognitive load and thus reduce designers' overall processing capacity (Evans \& Stanovich, 2013). This follows studies of multi-media instruction where the presentation of information has been shown to have a critical impact on its processing (Mayer \& Moreno, 2003). In the design context, Sun and Yao (2012) highlight how increased load can influence novelty and quantity during creative ideation. Here, designers iteratively ideate from a given stimuli, reflect, and reframe (Gonçalves et al., 2016; Hay et al., 2017). This cycle of iterative exploration and reflection is well established in design creativity and in design methods, and requires designers to both employ rapid intuitive idea generation, and more deliberative, reflective reframing in order to be successful (Gonçalves et al., 2016; Valkenburg \& Dorst, 1998). As such, increasing the load in terms of mental simulation could impact creative outcomes during ideation. However, Vasconcelos et al. (2017) found that while different stimuli did not impact overall fluency, they did shape the focus of the ideas produced. This leads to an ideation related hypothesis that might display mixed results across two key creativity measures (Shah, Smith, \& VargasHernandez, 2003).

Ideation: Matched input/response will lead to better ideation, measured via: H1F i) functional novelty and ii) overall number of ideas.

\subsection{Intuitive responses directed by representation mode}

Critical to the hypotheses in this section is the distinction between the explicit information content of an input and the implicit information associated with its representation mode (Cash \& Maier, 2016; GoldinMeadow, 1999). This distinction is illustrated by a number of observations in design. For example, Eris et al. (2014) highlight the communication of information distinct to gestures compared to verbalisations or sketches. Bekker, Olson, and Olson (1995) describe how kinetic gestures can describe interactions between user and product, and Linsey et al. (2011) note the implicit geometric information found in sketches. Here, representation mode conveys implicit information regarding knowledge structure and focus of attention (Kelly \& Gero, 2014; Roth, 2001). Specifically, gesture has been associated with implicit focus on spatial and dynamic elements (Chu \& Kita, 2011; Garber \& Goldin-Meadow, 2002). Critically, such implicit information typically acts on Type 1 intuitive processing by triggering association (Evans \& Stanovich, 2013).

Intuitive processing can be linked to descriptions of fixation (Crilly \& Cardoso, 2017; Vasconcelos \& Crilly, 2016) and creativity in design (Dane \& Pratt, 2007; Sowden, Pringle, \& Gabora, 2015). Stanovich et al. (2012) postulate that Type 1 and 2 processing continuously interact during generative tasks, with Type 2 processing able to override intuitive responses. More generally, designers combine intuitive and reflective periods during creative tasks (Gonçalves et al., 2016; Hay et al., 2017). Therefore, intuitive responses could interact with analytical responses driven by explicit information content (as in Hypothesis 1) (Sowden et al., 2015; Stanovich et al., 2012) and thus their effects may mediate rather than dominate the final response. For example, during ideation explicit information content will form direct stimuli for ideas and thus affect overall 
novelty and idea production as in $\mathrm{H} 1 \mathrm{~F}$, while implicit information regarding spatial and dynamic features (gesture) verses layout (sketch) might shape direction of focus as in H2E. Such interactions might also help explain the high degree of variation in fixation studies (Sio, Kotovsky, \& Cagan, 2015; Vasconcelos \& Crilly, 2016). Hence, we would expect implicit modal information to prompt simple association biases related to the input mode. In the context of design this can be operationalised in terms of measures that distinguish bias toward associations with spatial and dynamic features. For instance, three-dimensional and alternative views, movements, and kinetics as highlighted by gestures versus layout and form features, two-dimensional layout views, and structure, as highlighted by sketches. While this does not reflect a categorical differentiation between sketching and gestures, prior work has shown that each favour one or other type of information (Chu \& Kita, 2011; Davis, 2016). In particular, design students are trained to produce 2D views to represent layouts and 3D views to represent spatial characteristics and kinetics (Steur, 2019). Therefore, this distinction in output can provide information on designers' implicit interpretation of an input. This leads to five hypotheses:

Reproduction: Implicit modal information will prompt associations with spatial characteristics, measured via: $\mathbf{H 2 A}$ overall rate of $2 D$ versus $3 D$ representation in response; $\mathrm{H} 2 \mathrm{~B}$ bias in identification of functions.

Elaboration: Implicit modal information will prompt associations with spatial characteristics, measured via: H2C bias in elaboration of spatial and dynamic elements; and H2D bias in elaboration of i) functions and ii) features.

Ideation: Implicit modal information will prompt associations with spatial characteristics, measured via: H2E bias in creation of i) functions and ii) features.

While the underlying logic associated with Hypothesis 2 and it sub-hypotheses is grounded in well-evidenced accounts of Type 1 processing, there are two major caveats that should be highlighted here. First, the interaction between Type 1 and Type 2 processing is complex and can lead to a range of possible outcomes in terms of balance between analytical and intuitive responses (Badke-Schaub \& Eris, 2014; Sowden et al., 2015; Stanovich et al., 2008). Second, following this complexity, the empirical findings and operationalisation of intuition and fixation type effects in design creativity show a wide range of - often conflicting - results (Crilly \& Cardoso, 2017; Sio et al., 2015; Vasconcelos \& Crilly, 2016). Thus, the impact of representation mode on final outcomes is more ambiguous than in Hypothesis 1.

\subsection{Potential confounds and analytical processing}

Finally, there are a wide range of contrasting findings in design research that could complicate the dualprocessing hypotheses described above. Specifically, design related representational inputs require some Type 2 processing in order to understand and respond to their explicit information content, consistent with 
prior work on uncertainty (Ball \& Christensen, 2019; Cash \& Kreye, 2017). During judgement focused tasks such as evaluation and selection both Type 1 and Type 2 processes are engaged (Evans \& Stanovich, 2013; Stanovich et al., 2012). Here, there is a focus on analytical processes directed towards explicit goals (Norman et al., 2017; Thoma, White, Panigrahi, Strowger, \& Anderson, 2015). For example, many design tools are targeted at supporting this type of processing (Akinci \& Sadler-Smith, 2019; Norman et al., 2017). Generally, there is focus on deliberate judgement and decision making against goal criteria (Cross, 2008; Toh, Miele, \& Miller, 2015), particularly regarding feasibility and functionality (Toh \& Miller, 2015), which are also linked to perception of performance (Hoegg \& Alba, 2011). Therefore, if the explicit information content is equivalent, Type 2 processing should deliver similar judgements.

Examples of such contrasting findings in design include, Linsey et al. (2011) and Toh and Miller (2014) who found that different stimuli resulted in different levels of fluency during ideation, while Vasconcelos et al. (2017) found no effect. Similarly, Toh et al. (2015) suggest potential gender related ownership bias during idea selection, while Stark and Perfect $(2007,2008)$ identify other effects stemming from degree of idea development. A number of studies have found a seemingly unconscious bias against the selection of creative ideas (Mueller, Melwani, \& Goncalo, 2012; Starkey, Toh, \& Miller, 2016), while others have found that, when explicitly prompted, people were able to override such biases, at the cost of decreased satisfaction and perceived idea effectiveness (Rietzschel, Nijstad, \& Stroebe, 2010). Further, Kudrowitz et al. (2012) describe a link between the quality of an idea representation (comparing sketches) and its perceived creativity. Thus, it is perhaps unsurprising that there are contrasting accounts of the overall impact of representational action on design outcomes (Bilda, Gero, \& Purcell, 2006; Van Der Lugt, 2005; Yang, 2005, 2009).

Given this diversity in prior results it is essential that we differentiate underlying dual-process mechanisms from other study methodology or contextual factors (Cash \& Culley, 2014). For example, Linsey et al. (2011) note that there was additional information content associated with one representation mode in their study, which could confound the processing explanation offered in this section. Therefore, by controlling for dualprocessing related confounds we can potentially expose common mechanisms underlying previously conflicting design results. Thus, we formulate three 'checks' where we expect no significant differences when controlling for information content.

Check 1 (C1): Evaluation: Controlled explicit information content will lead to equivalent evaluation performance, measured via identification of i) strengths, ii) weaknesses, iii) feasibility and iv) ranking of concepts.

Check 2 (C2): Elaboration: Controlled explicit information content will lead to equivalent concept ownership, measured via perception of i) ownership, ii) attachment, iii) self-extension, and iv) satisfaction. 
Check 3 (C3): Selection: Controlled explicit information content will lead to equivalent idea ownership, measured via bias toward selection of own ideas for development after ideation.

Given our research aim, we adopt a multi-part experimental approach. The three experimental studies are summarised in Table 1, with Study I and III comprising two parts ( $a$ and b). In order to increase generalisability to the design literature, reduce complexity, and increase robustness the experimental designs and measures were, wherever possible, adapted from prior studies. In all cases, a student sample was used to maximise internal validity as well as comparability with prior studies, which also utilised students. Students are relatively homogeneous and good at following complex study designs, and thus ideal for isolating causal effects, internal validity, and statistical validity (Bello, Leung, Radebaugh, Tung, \& Van Witteloostuijn, 2009). All samples were sized in order to provide a minimum conditional $\mathrm{N}$ of $\sim 30$ following best practice sample size guidance for experimental studies (Onwuegbuzie \& Collins, 2007). Finally, the starting point for all experiments was to work with a camera mounting system for an aerial drone, utilising a similar task to that already validated by Cash et al. (2013). Each study was scripted to avoid facilitation bias and all experimental protocols are provided in the appendix.

Table 1: Overview experimental studies

\begin{tabular}{|c|c|c|c|}
\hline Experiment & Sample demographics & Study design & Sketch / Gesture N \\
\hline $\begin{array}{l}\text { Study la: Reproduction } \\
\text { Study Ib: Evaluation }\end{array}$ & \multirow{4}{*}{$\begin{array}{c}\text { University design and } \\
\text { innovation students } \\
44 \% \text { female; mean age } 23.7 \\
\text { years, SD 3.5; mean work } \\
\text { experience } 8.8 \text { months, SD } \\
11.5\end{array}$} & $\begin{array}{c}\text { Within group } \\
\text { counterbalanced A v. B }\end{array}$ & $\begin{array}{c}\mathrm{N}=122 \text { across four } \\
\text { conditions }\end{array}$ \\
\hline Study II: Elaboration & & \multirow[t]{3}{*}{ Between group A v. B } & $N=32 / N=41$ \\
\hline Study IIla: Ideation & & & $N=55 / N=44$ \\
\hline Study IIIb: Selection & & & $N=44 / N=43$ \\
\hline
\end{tabular}

\subsection{Study I: Reproduction and Evaluation}

In this study, participants were asked to watch two sets of videos. Each set showed a person describing three concepts for a camera mounting system to be attached to a drone, and was repeated three times. Each short description lasted 20 seconds and was based on the descriptions of concept explanations provided by Cash and Maier (2016). Participants were then asked to complete a small distractor task (filling in demographic information) before being asked to reproduce the concepts they had been shown as accurately as possible, list their main functions, and evaluate their strengths, weakness, and feasibility (using the scoring system described by Linsey et al. (2011, fig. 7) (Table 2). After completing this task for the first set, study participants were asked to rank the concepts in terms of feasibility, novelty, and which was 'best'. Once complete, they watched the second set following the same procedure (see Appendix A). The two sets comprised six concepts in total, with one set using gesture and verbalisation and the other sketching and verbalisation, again based on Cash and Maier (2016). In order to control for ordering or learning effects a within group counterbalanced design was used (Kirk, 2009), with four conditions as illustrated in Figure 2. 

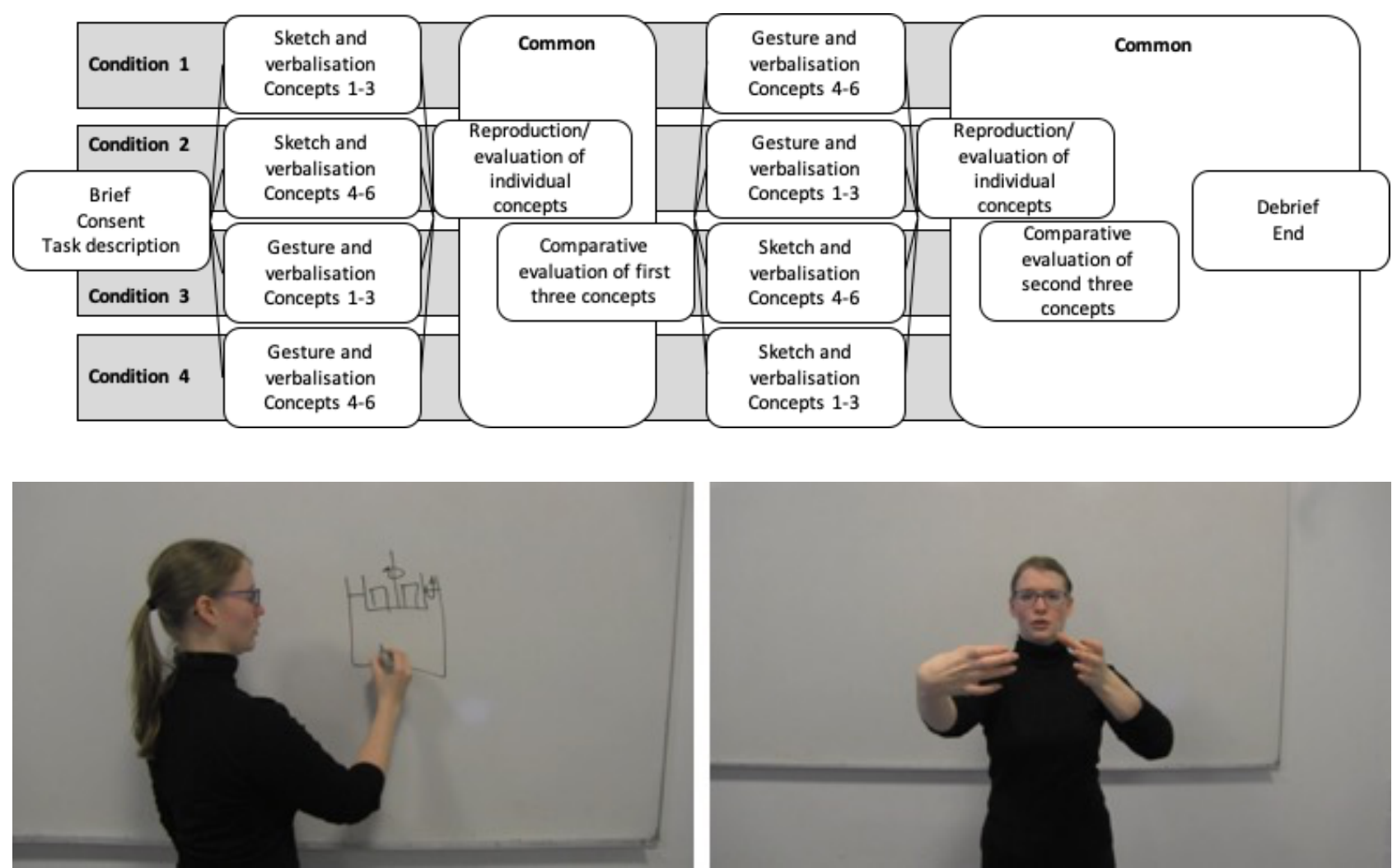

Figure 2: Structure of Study I with example stills from the concept description videos

\subsection{Study II: Elaboration}

In this study, participants were asked to watch one of two possible videos. This comprised the gesture and sketching videos for the concept that was most memorable in Study I. Participants were then asked to build on the video to create one single concept and develop and detail this as much as possible in 20 minutes (Sevier et al., 2017). As part of this elaboration they were also requested to describe functionality, durability, and ease of use. Once elaboration was finished, participants were asked to complete a number of Likert-type instruments drawn from prior work, to evaluate their sense of ownership over the concept (Table 2 and Appendix B). Elaboration of the concept was evaluated based on prior measures described by Toh and Miller (2014, fig. 4) and Sevier et al. (2017, op. 8) (Table 2). In order to test the differences between the two conditions a between-group design was used (Kirk, 2009). The basic structure, framing, and specific protocol instructions for the study instructions were based on the 'visual inspection' task described by Toh and Miller (2014, p. 3). Study II followed the structure in Figure 3.

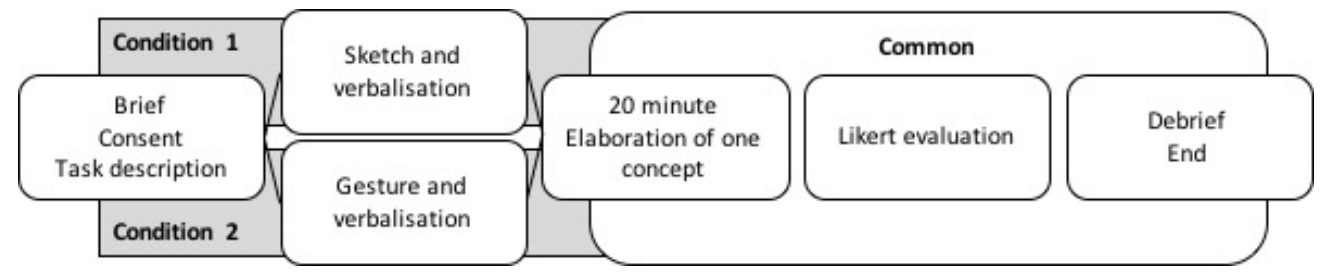

Figure 3: Structure of Study II 


\subsection{Study III: Ideation and Selection}

In this study, participants were again asked to watch one of two possible videos, as in Study II. The participants were then asked to ideate on the concept, i.e. create as many different ideas as possible, following similar creativity studies (Gonçalves et al., 2016). Subsequent to this, they had a three-hour break followed by a selection task. The design of this study replicated the work of Starkey et al. (2016), but with the previously described camera mounting problem and two conditions, as in Figure 4 (see Appendix C). This also aligns with a number of similar works (Starkey et al., 2016; Toh, Miele, et al., 2015; Toh \& Miller, 2015) and provides the opportunity to replicate the gender based self-selection effects reported by Toh et al. (2015). Ideation measurement followed the fluency and novelty evaluations described by Vasconcelos et al. (2017) while selection evaluation followed the round table 'consider/do not consider' procedure of Toh et al. (2015) (Table 2). As in Study II a between groups design was used (Kirk, 2009).

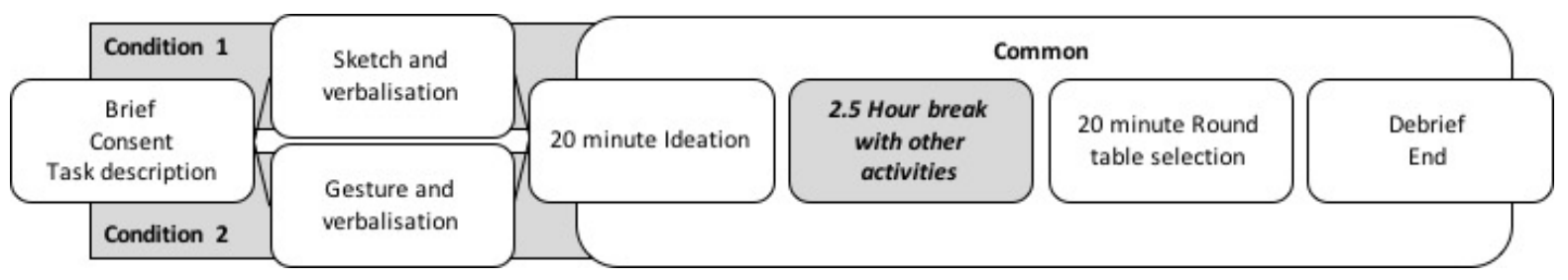

Figure 4: Structure of Study III

\subsection{Experimental Measures}

Five main types of measures were used in this research: counts, schema, word tags, participant rating, and calculations (Table 2). The first three types (counts, schema, and word tags) were evaluated by a hypothesis blind rater (with a master's degree in design and industrial experience), denoted as 'rater-coded' in Table 2. The latter two types (participant rating and calculations primarily related to C1-3) directly followed participant inputs, e.g. via Likert scales. A summary of all measures is provided in Table 2, while Appendix D gives example coding and details of schemas and Likert scales. For the rater-evaluated measures, we provide additional details of procedure and reliability below.

\section{Count measures}

Count measures were evaluated based on the participants' sketches and include: H1A (reproductions), H1C (use of $3 \mathrm{D}$ ), $\mathrm{H} 1 \mathrm{~B}$ and $\mathrm{H} 1 \mathrm{C}$ (parts and movements), and $\mathrm{H} 2 \mathrm{C}$ (various sketch elements). All of these measures were directly manifest in the sketches and relatively simple to identify, as illustrated by the examples in Appendix D. Sketches were easily interpretable by a rater with design experience. The rating process followed five steps: i) rater training by the first author, ii) rater and first author independently annotated $5 \%$ of the Study I sketches, iii) comparison revealed $100 \%$ agreement, iv) results discussed with second author to ensure 
consistency, v) the rater evaluated all remaining sketches. The high agreement can be attributed to the manifest measures and simplicity of the participant sketches.

\section{Schema measures}

Schema measures were primarily evaluated based on the participants' sketches but also included descriptions in the provided text boxes and included: H1D (topology and mode of action), C1 and H1E (quality), and H1E (originality). Each of these measures followed specific coding schema detailed in Table 2 and Appendix D. Due to the simplicity of the sketches, interpretation was again found to be highly consistent. The rating process followed the same steps as detailed for the count measures. However, in this case an iteration was needed in step iii for topology and mode of action. Initial agreement for these measures was $\sim 80 \%$ and hence after discussion with the second author, step ii was repeated on a different $5 \%$ of the Study I sketches. This resulted in $100 \%$ agreement and rating proceeded for the remaining data.

\section{Word tag measures}

Word tag measures were evaluated based on various aspects of the results as detailed in Table 2 and included: H2B, C1, H1E, H2C, H2D, H1F, H2E. Here, words were allocated to tags in two overall stages following an iterative inductive process (Miles \& Huberman, 1994). First: i) the rater organised the words, removed repetitions, and clustered synonyms, ii) the rater carried out an initial clustering, iii) clustering was iterated in a workshop with the authors. Steps ii and iii were iterated until the research team agreed on all tag allocations. For subsequent studies, the allocation of words from Study I were used as a basis for tagging. Any new words were iteratively allocated, as above, until agreement was reached. 
Table 2: Overview experimental measures

\begin{tabular}{|c|c|c|c|}
\hline Task & & Measure description & Data type \\
\hline \multirow{14}{*}{ Reproduction } & \multirow{2}{*}{$\mathrm{H} 1 \mathrm{~A}$} & Number of successfully reproduced examples from 0 to 6 & Gesture/sketched v. success/failure \\
\hline & & Rater-coded based on completion of a sketch within the provided & Appendix A), typically boxes were either complete or blank \\
\hline & \multirow{2}{*}{ H1B } & Total number of reproduced parts and movements & Difference in means \\
\hline & & Rater-coded based on sketch details and explicit use of directional & examples in Appendix D) \\
\hline & \multirow{6}{*}{ H1D } & Difference in reproduced parts/movements from number in input & Difference in means \\
\hline & & Rater-coded based on comparison between sketch details and the & ept (see base concepts and examples in Appendix D) \\
\hline & & Difference in reproduced topology from the input & Difference in means \\
\hline & & Rater-coded based on comparison between sketch details in same & ove and the original concept (see schema in Appendix D) \\
\hline & & Difference in reproduced mode of action from the input & Difference in means \\
\hline & & Rater-coded based on comparison between sketch details in same & ve and the original concept (see schema in Appendix D) \\
\hline & \multirow{2}{*}{$\mathrm{H} 2 \mathrm{~A}$} & Number of responses represented in 3D & Gesture/sketched v. 3D/2D \\
\hline & & Rater-coded based on sketch details and explicit use of 3D drawing & aples in Appendix D) (Sevier et al., 2017, p. 8) \\
\hline & \multirow{2}{*}{$\mathrm{H} 2 \mathrm{~B}$} & Number of identified functions related to spatial characteristics & Gesture/sketched v. spatial/non-spatial \\
\hline & & Rater-coded based wording in provided blanks (see Appendix A) e. & rning", "joint rotation" / "3 motors", "wireless control" \\
\hline \multirow{8}{*}{ Evaluation } & \multirow{8}{*}{$\mathrm{C} 1$} & Number of identified strengths related to spatial characteristics & Gesture/sketched v. spatial/non-spatial \\
\hline & & Rater-coded as with H2B e.g. "vertical movement", "360 rotation", & ee of freedom" / "fixed camera", "few parts", "easy control" \\
\hline & & Number of identified weaknesses related to spatial characteristics & Gesture/sketched v. spatial/non-spatial \\
\hline & & Rater-coded as with H2B e.g. "low rotation", "difficult to move", "li & iement" / "2 motors", "wind sensitive", "not well protected" \\
\hline & & Scored evaluation of feasibility 'quality scale' $0-2$ & Gesture/sketched v. 0/1/2 \\
\hline & & Based on participant responses to questions 4 and 5 e.g. on page 5 & $\operatorname{dix}$ A (Linsey et al., 2011, fig. 7) \\
\hline & & Ranked ordering in selection of 'best' concepts & Gesture/sketched v. rank order \\
\hline & & Based on participant selection of concept to develop further, ques & age 15 of Appendix $A$ \\
\hline \multirow{12}{*}{ Elaboration } & \multirow{6}{*}{$\mathrm{H} 1 \mathrm{C}$} & Number of functions described in elaborated concept & Difference in means \\
\hline & & Rater-coded based on sketches and notes in provided boxes in App & sing list of functions established in $\mathrm{H} 2 \mathrm{~B}$ \\
\hline & & Number of parts described in elaborated concept & Difference in means \\
\hline & & Rater-coded following H1B based on sketches in provided boxes in & B, see example in Appendix D \\
\hline & & Number of movements described in elaborated concept & Difference in means \\
\hline & & Rater-coded following H1B based on sketches in provided boxes in & B, see example in Appendix D \\
\hline & \multirow{4}{*}{ H1E } & Score evaluation of quality 'quality score' 0-4 & Rank score \\
\hline & & Rater-coded in comparison to the base concept denoted at the sta & ndix D (Toh \& Miller, 2014, fig. 4) \\
\hline & & Evaluation of originality in response & Gesture/sketched v. copy/incremental/new \\
\hline & & Rater-coded in comparison to the base concept denoted at the sta & ndix D (see schema in Appendix D) \\
\hline & \multirow{2}{*}{$\mathrm{H} 2 \mathrm{C}$} & Use of 3D spatial elements in concept sketch & 3D binary \\
\hline & & Rater-coded following H2A based on sketch details and use of "dim & depth, width, and height" (Sevier et al., 2017, p. 8) \\
\hline
\end{tabular}




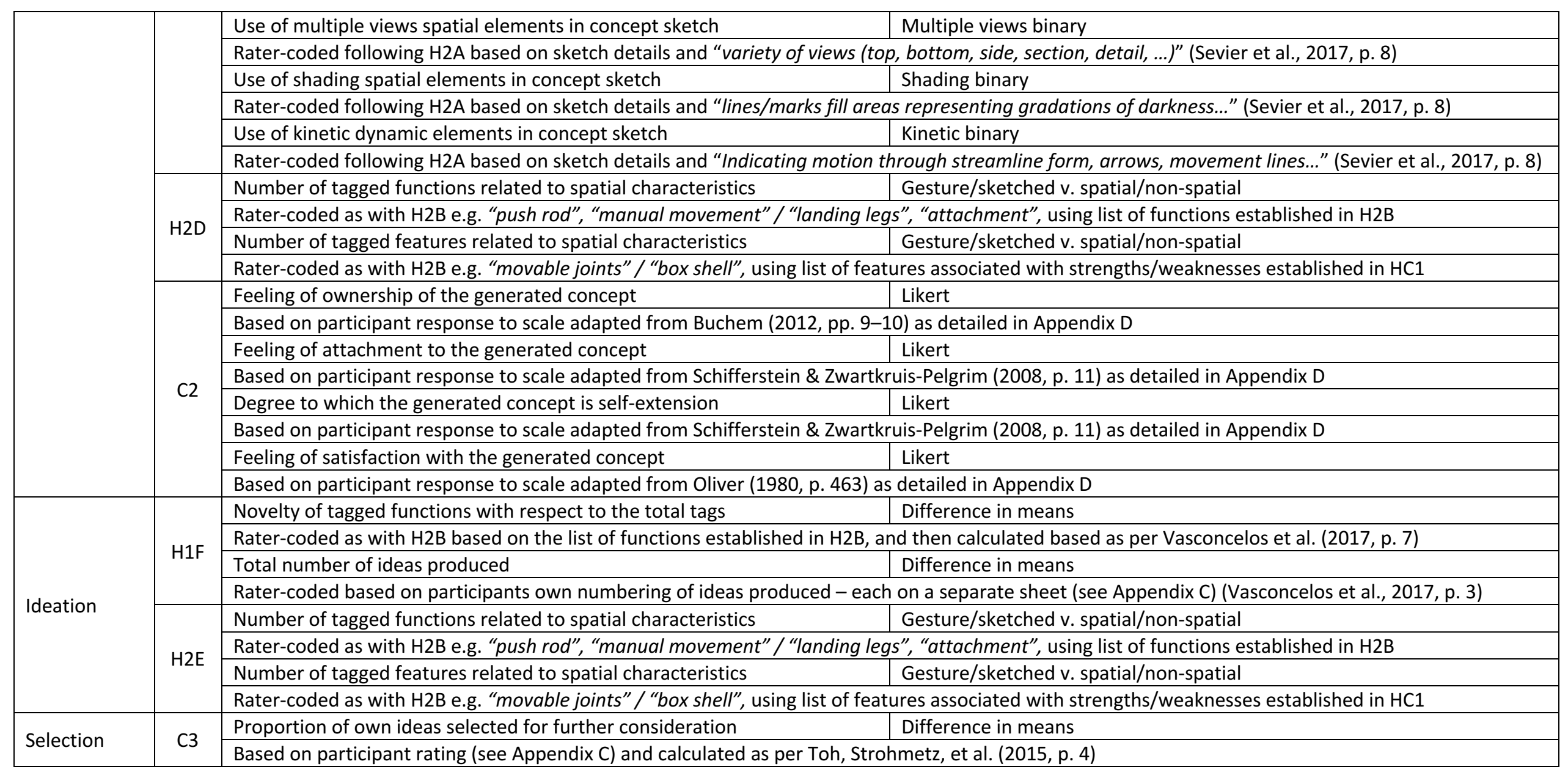


In this section we draw together the results from across experiments in order to test the hypotheses.

\subsection{Testing the impact of matched verses mismatched input/response}

Our first set of measures provides robust support for all elements of Hypothesis 1, as summarised in Table 3. For H1A-C results were consistent across the six concepts included in Study I. From this set, four measures were not supported. Specifically, we observed no significant difference in the number of parts and movements developed during elaboration, rather than the expected reduction. However, this was balanced by a strong effect in terms of number of functions developed. Second, we observed no significant difference in overall quality score after elaboration using a 2-tailed test, while a 1-tailed test aligned with the direction of the hypothesis does reveal a marginally significant effect i.e. $p=.067$. This could be partially attributed to overall feasibility scoring being relatively high, with few responses scored 0 or 1 . Finally, as speculated with respect to H1F (Section 2.1), we observed a significant difference in functional novelty, but no difference number of ideas. Thus, our results support Hypothesis 1.

With respect to the unsupported measures: $\mathrm{H} 1 \mathrm{C}$ number of parts and movements and $\mathrm{H} 1 \mathrm{~F}$ number of ideas, it is possible to offer tentative explanations consistent with the basic research framework (Figure 1). First, parts and movements are distinct from functions in that they relate to the layout and structure of the concept and thus their inclusion is, to a degree, prompted by the development of the output sketch itself i.e. a missing part or movement can become evident in order for the sketch to make visual sense. This is less likely for the identification of abstract functions, which are not required for visual sensemaking. Hence, further work is needed in order to evaluate if this discrepancy between functions and parts/movements is also evident for different types of response where the above confound might be mitigated.

Second, prior work in creativity implies that ideation fluency can stem from both Type 1 and Type 2 processing, involving both associative and analytical elements (Howard-Jones, 2002), while novelty or the nature of the ideas produced is much less well described. Hence, it is possible that differences in processing might impact novelty but not fluency and thus potentially explain the contrast between the number of ideas and novelty results. However, research on the specific effects of dual-process cognition in creativity as well as interactions between the various ideation metrics is still emerging and further work is needed.

Table 3: Overview results for Hypotheses 1A-F

\begin{tabular}{|c|c|c|c|c|}
\hline & Measure & Result & Descriptive statistics & Test and significance \\
\hline H1A & $\begin{array}{c}\text { Reproduction success } \\
\text { Gesture/sketched v. } \\
\text { success/failure }\end{array}$ & $\begin{array}{c}\text { Supported } \\
\text { Lower for mismatched }\end{array}$ & $\begin{array}{c}\text { success/failure } \\
\text { Gesture }=342(93 \%) / 24(7 \%) \\
\text { Sketch }=359(98 \%) / 7(2 \%)\end{array}$ & $\begin{array}{c}\text { Chi-squared test } \\
X^{2}=9.73 p=.002\end{array}$ \\
\hline H1B & Reproduced parts & $\begin{array}{c}\text { Supported } \\
\text { Lower for mismatched }\end{array}$ & $\begin{array}{c}\text { Gesture } m=5.06, \mathrm{SD}=2.59 \\
\text { Sketch } \mathrm{m}=6.05, \mathrm{SD}=2.33\end{array}$ & $\begin{array}{c}\text { Paired t-test (2-tail) } \\
p=.000\end{array}$ \\
\hline
\end{tabular}




\begin{tabular}{|c|c|c|c|c|}
\hline & $\begin{array}{l}\text { Reproduced } \\
\text { movements } \\
\end{array}$ & $\begin{array}{c}\text { Supported } \\
\text { Lower for mismatched }\end{array}$ & $\begin{array}{l}\text { Gesture } \mathrm{m}=1.71, \mathrm{SD}=1.80 \\
\text { Sketch } \mathrm{m}=2.18, \mathrm{SD}=1.64\end{array}$ & $\begin{array}{l}\text { Paired t-test (2-tail) } \\
\qquad p=.000\end{array}$ \\
\hline \multirow{3}{*}{$\mathrm{H} 1 \mathrm{C}$} & $\begin{array}{c}\text { Number of functions } \\
\text { developed }\end{array}$ & $\begin{array}{c}\text { Supported } \\
\text { Lower for mismatched }\end{array}$ & $\begin{array}{l}\text { Gesture } \mathrm{m}=2.87, \mathrm{SD}=1.26 \\
\text { Sketch } \mathrm{m}=3.90, \mathrm{SD}=1.60\end{array}$ & $\begin{array}{c}\text { t-test (2-tail) } \\
p=.004\end{array}$ \\
\hline & $\begin{array}{c}\text { Number of parts } \\
\text { developed }\end{array}$ & $\begin{array}{c}\text { Not Supported } \\
\text { No difference }\end{array}$ & $\begin{array}{l}\text { Gesture } \mathrm{m}=7.82, \mathrm{SD}=3.58 \\
\text { Sketch } \mathrm{m}=7.16, \mathrm{SD}=2.72\end{array}$ & $\begin{array}{c}t \text {-test (2-tail) } \\
p=.399\end{array}$ \\
\hline & $\begin{array}{c}\text { Number of movements } \\
\text { developed }\end{array}$ & $\begin{array}{l}\text { Not Supported } \\
\text { No difference }\end{array}$ & $\begin{array}{l}\text { Gesture } \mathrm{m}=2.08, \mathrm{SD}=.77 \\
\text { Sketch } \mathrm{m}=2.10, \mathrm{SD}=.87\end{array}$ & $\begin{array}{c}t \text {-test (2-tail) } \\
p=.920\end{array}$ \\
\hline \multirow{4}{*}{ H1D } & $\begin{array}{c}\text { Deviance from input: } \\
\text { number of parts }\end{array}$ & $\begin{array}{c}\text { Supported } \\
\text { Higher for mismatched } \\
\end{array}$ & $\begin{array}{c}\text { Gesture } m=-3.20, S D=2.91 \\
\text { Sketch } m=-2.36, S D=2.17\end{array}$ & $\begin{array}{l}\text { Paired t-test (2-tail) } \\
\qquad p=.000\end{array}$ \\
\hline & $\begin{array}{l}\text { Deviance from input: } \\
\text { number of movements }\end{array}$ & $\begin{array}{c}\text { Supported } \\
\text { Higher for mismatched } \\
\end{array}$ & $\begin{array}{c}\text { Gesture } m=-1.64, S D=1.36 \\
\text { Sketch } m=-1.13, S D=1.14\end{array}$ & $\begin{array}{l}\text { Paired t-test (2-tail) } \\
\qquad p=.000\end{array}$ \\
\hline & $\begin{array}{c}\text { Deviance from input: } \\
\text { topology }\end{array}$ & $\begin{array}{c}\text { Supported } \\
\text { Higher for mismatched }\end{array}$ & $\begin{array}{l}\text { Gesture } \mathrm{m}=2.24, \mathrm{SD}=1.05 \\
\text { Sketch } \mathrm{m}=1.49, \mathrm{SD}=1.15\end{array}$ & $\begin{array}{l}\text { Paired t-test (2-tail) } \\
\qquad p=.000\end{array}$ \\
\hline & $\begin{array}{l}\text { Deviance from input: } \\
\text { mode of action }\end{array}$ & $\begin{array}{c}\text { Supported } \\
\text { Higher for mismatched }\end{array}$ & $\begin{array}{l}\text { Gesture } \mathrm{m}=1.77, \mathrm{SD}=1.51 \\
\text { Sketch } \mathrm{m}=1.02, \mathrm{SD}=1.39\end{array}$ & $\begin{array}{l}\text { Paired t-test (2-tail) } \\
\qquad p=.000\end{array}$ \\
\hline \multirow[b]{2}{*}{ H1E } & $\begin{array}{l}\text { Overall quality } \\
\text { Rank score }\end{array}$ & $\begin{array}{l}\text { Not Supported } \\
\text { No difference }\end{array}$ & $\begin{array}{l}\text { Gesture } m=3.33, S D=.58 \\
\text { Sketch } m=3.06, S D=.77\end{array}$ & $\begin{array}{c}\text { Mann-Whitney U test } \\
\text { (2-tail) } \\
U=495 p=.133\end{array}$ \\
\hline & $\begin{array}{l}\text { Originality in response } \\
\text { Gesture/sketched v. } \\
\text { copy/incremental/new }\end{array}$ & $\begin{array}{c}\text { Supported } \\
\text { Higher for mismatched }\end{array}$ & $\begin{array}{c}\text { copy/incremental/new } \\
\text { Gesture }=20(34 \%) / 15 \\
(25 \%) / 24(41 \%) \\
\text { Sketch = } 22(40 \%) / 21 \\
(38 \%) / 12(22 \%)\end{array}$ & $\begin{array}{c}\text { Chi-squared test } \\
X^{2}=89.58 p=.000\end{array}$ \\
\hline \multirow{2}{*}{ H1F } & Functional novelty & $\begin{array}{c}\text { Supported } \\
\text { Lower for mismatched }\end{array}$ & $\begin{array}{l}\text { Gesture } m=1.44, S D=.37 \\
\text { Sketch } m=1.66, S D=.46\end{array}$ & $\begin{array}{l}\text { t-test (2-tail) } \\
\quad p=.014\end{array}$ \\
\hline & Number of ideas & $\begin{array}{c}\text { Not Supported } \\
\text { No difference }\end{array}$ & $\begin{array}{l}\text { Gesture } m=5.73, S D=2.08 \\
\text { Sketch } m=5.45, S D=1.60\end{array}$ & $\begin{array}{c}\text { t-test (2-tail) } \\
p=.463\end{array}$ \\
\hline
\end{tabular}

\subsection{Testing the impact of implicit modal information}

Our second set of measures provides credible support for Hypothesis 2 across design tasks, with four submeasures not being supported and two only marginally supported, as summarised in Table 4. Specifically, multiple views and shading were only marginally significant using a 2-tailed test, despite strong support for the other measures in $\mathrm{H} 2 \mathrm{C}$. However, a 1-tailed test aligned with the direction of the hypothesis does reveal an effect, $p=.039$ and $p=.046$ respectively. Therefore, these can be considered marginal support for H2C. Further, we observed no significant differences for H2D and H2E. However, these are in contrast to spatially focused responses to H2C. Thus, our results tentatively support Hypothesis 2.

With respect to the unsupported measures in $\mathrm{H} 2 \mathrm{D}$ and $\mathrm{H} 2 \mathrm{E}$, it is again possible to offer tentative explanations consistent with our research framework. Specifically, it is possible that the act of sketching, which is normally not deliberately rationalised, is more reliant on intuitive processing than the detailing and description of specific functions and features. Hence, the contrast between the results for $\mathrm{H} 2 \mathrm{C}$, where the sketches themselves are found to show distinct differences, and H2D and H2E, where no differences are observed in the specific functions and features described. However, further work is needed to explore the types of processing involved with different aspects of design work and how those interact during a design task.

Table 4: Overview results for Hypotheses $2 \mathrm{~A}-\mathrm{E}$

Measure $\quad$ Result




\begin{tabular}{|c|c|c|c|c|}
\hline H2A & $\begin{array}{c}\text { Rate of 3D response } \\
\text { Gesture/sketched v. } \\
\text { 3D/2D }\end{array}$ & $\begin{array}{c}\text { Supported } \\
\text { Higher in gestured }\end{array}$ & $\begin{array}{c}3 D / 2 D \\
\text { Gesture }=110(32 \%) / 232(68 \%) \\
\text { Sketch }=2(1 \%) / 357(99 \%)\end{array}$ & $\begin{array}{c}\text { Chi-squared test } \\
X^{2}=130.34 p=.000\end{array}$ \\
\hline H2B & $\begin{array}{c}\text { Functions } \\
\text { Gesture/sketched v. } \\
\text { spatial/non-spatial }\end{array}$ & $\begin{array}{c}\text { Supported } \\
\text { Higher in gestured }\end{array}$ & $\begin{array}{c}\text { spatial/non-spatial } \\
\text { Gesture }=219(48 \%) / 237(52 \%) \\
\text { Sketch }=179(38 \%) / 288(62 \%)\end{array}$ & $\begin{array}{l}\text { Chi-squared test } \\
\mathrm{X}^{2}=8.84 p=.003\end{array}$ \\
\hline \multirow{4}{*}{$\mathrm{H} 2 \mathrm{C}$} & $\begin{array}{c}\text { Elaboration of spatial } \\
\text { elements } \\
\text { 3D binary }\end{array}$ & $\begin{array}{c}\text { Supported } \\
\text { Higher in gestured }\end{array}$ & $\begin{array}{l}\text { Gesture }=74 \% \\
\text { Sketch }=36 \%\end{array}$ & $\begin{array}{l}2 \text { Sample Z Test for } \\
\text { proportions } \\
z=3.04 p=.002 \\
\end{array}$ \\
\hline & $\begin{array}{l}\text { Elaboration of spatial } \\
\text { elements } \\
\text { Multiple views binary }\end{array}$ & $\begin{array}{c}\text { Marginally } \\
\text { Supported } \\
\text { Higher in gestured }\end{array}$ & $\begin{aligned} \text { Gesture } & =15 \% \\
\text { Sketch } & =3 \%\end{aligned}$ & $\begin{array}{c}2 \text { Sample Z Test for } \\
\text { proportions } \\
z=1.77 p=.077\end{array}$ \\
\hline & $\begin{array}{c}\text { Elaboration of spatial } \\
\text { elements } \\
\text { Shading binary } \\
\end{array}$ & $\begin{array}{c}\text { Marginally } \\
\text { Supported } \\
\text { Higher in gestured }\end{array}$ & $\begin{array}{l}\text { Gesture }=69 \% \\
\text { Sketch }=48 \%\end{array}$ & $\begin{array}{c}2 \text { Sample Z Test for } \\
\text { proportions } \\
z=1.68 p=.092\end{array}$ \\
\hline & $\begin{array}{c}\text { Elaboration of dynamic } \\
\text { elements } \\
\text { Kinetic binary } \\
\end{array}$ & $\begin{array}{c}\text { Supported } \\
\text { Higher in gestured }\end{array}$ & $\begin{array}{l}\text { Gesture }=74 \% \\
\text { Sketch }=45 \%\end{array}$ & $\begin{array}{l}2 \text { Sample } Z \text { Test for } \\
\text { proportions } \\
z=2.49 p=.013\end{array}$ \\
\hline \multirow{2}{*}{ H2D } & $\begin{array}{c}\text { Functions } \\
\text { Gesture/sketched v. } \\
\text { spatial/non-spatial } \\
\end{array}$ & $\begin{array}{l}\text { Not Supported } \\
\text { No difference }\end{array}$ & $\begin{array}{c}\text { spatial/non-spatial } \\
\text { Gesture }=50(74 \%) / 18(26 \%) \\
\text { Sketch }=46(74 \%) / 16(26 \%)\end{array}$ & $\begin{array}{l}\text { Chi-squared test } \\
X^{2}=.01 p=.931\end{array}$ \\
\hline & $\begin{array}{c}\text { Features } \\
\text { Gesture/sketched v. } \\
\text { spatial/non-spatial }\end{array}$ & $\begin{array}{l}\text { Not Supported } \\
\text { No difference }\end{array}$ & $\begin{array}{c}\text { spatial/non-spatial } \\
\text { Gesture }=47(51 \%) / 46(49 \%) \\
\text { Sketch }=41(55 \%) / 34(45 \%)\end{array}$ & $\begin{array}{l}\text { Chi-squared test } \\
X^{2}=.28 p=.594\end{array}$ \\
\hline \multirow{2}{*}{ H2E } & $\begin{array}{c}\text { Functions } \\
\text { Gesture/sketched v. } \\
\text { spatial/non-spatial }\end{array}$ & $\begin{array}{l}\text { Not Supported } \\
\text { No difference }\end{array}$ & $\begin{array}{c}\text { spatial/non-spatial } \\
\text { Gesture }=274(71 \%) / 113(29 \%) \\
\text { Sketch }=363(67 \%) / 178(33 \%)\end{array}$ & $\begin{array}{l}\text { Chi-squared test } \\
X^{2}=1.44 p=.231\end{array}$ \\
\hline & $\begin{array}{c}\text { Features } \\
\text { Gesture/sketched v. } \\
\text { spatial/non-spatial }\end{array}$ & $\begin{array}{l}\text { Not Supported } \\
\text { No difference }\end{array}$ & $\begin{array}{l}\text { spatial/non-spatial } \\
\text { Gesture }=273(76 \%) / 87(24 \%) \\
\text { Sketch }=364(74 \%) / 130(26 \%)\end{array}$ & $\begin{array}{l}\text { Chi-squared test } \\
X^{2}=.51 p=.476\end{array}$ \\
\hline
\end{tabular}

\subsection{Checking explicit information content}

Our final set of measures robustly supported all three checks (C1-3 Section 2.3), as summarised in Table 5. Here, expectations of equivalent responses to gestured and sketched inputs when controlling for explicit information content were observed across all measures. This suggests effective control of this factor was achieved across design tasks. Further, these results lend support to the idea that conflicts in prior design findings might be derived from factors other than basic processing response. Thus, the checks lend support to the findings for Hypotheses 1 and 2.

Table 5: Overview results for the three checks C1-3

\begin{tabular}{|c|c|c|c|c|}
\hline & Measure & Result & Descriptive statistics & Test and significance \\
\hline \multirow{3}{*}{ C1 } & $\begin{array}{c}\text { Strengths } \\
\text { Gesture/sketched v. } \\
\text { spatial/non-spatial }\end{array}$ & No difference & $\begin{array}{c}\text { spatial/non-spatial } \\
\text { Gesture }=52(23 \%) / 179(77 \%) \\
\text { Sketch }=62(25 \%) / 189(75 \%)\end{array}$ & $\begin{array}{l}\text { Chi-squared test } \\
X^{2}=.32 p=.572\end{array}$ \\
\hline & $\begin{array}{c}\text { Weaknesses } \\
\text { Gesture/sketched v. } \\
\text { spatial/non-spatial }\end{array}$ & No difference & $\begin{array}{c}\text { spatial/non-spatial } \\
\text { Gesture }=68(24 \%) / 220(76 \%) \\
\text { Sketch }=72(25 \%) / 218(75 \%)\end{array}$ & $\begin{array}{l}\text { Chi-squared test } \\
X^{2}=.12 p=.733\end{array}$ \\
\hline & $\begin{array}{c}\text { Feasibility } \\
\text { Gesture/sketched v. } \\
0 / 1 / 2\end{array}$ & No difference & $\begin{array}{c}\text { score } 0 / 1 / 2 \\
\text { Gesture }=125(34 \%) / 109 \\
(30 \%) / 132(36 \%)\end{array}$ & $\begin{array}{l}\text { Chi-squared test } \\
X^{2}=1.34 p=.512\end{array}$ \\
\hline
\end{tabular}




\begin{tabular}{|c|c|c|c|c|}
\hline & & & $\begin{array}{c}\text { Sketch }=113(31 \%) / 122 \\
(33 \%) / 131(36 \%)\end{array}$ & \\
\hline & $\begin{array}{c}\text { Concept ranking } \\
\text { Gesture/sketched v. } \\
\text { rank order }\end{array}$ & No difference & $\begin{array}{c}\operatorname{rank} 1 / 2 / 3 \\
\text { Gesture }=40(36 \%) / 38 \\
(34 \%) / 34(30 \%) \\
\text { Sketch }=53(48 \%) / 24(22 \%) / 34 \\
(31 \%)\end{array}$ & $\begin{array}{l}\text { Chi-squared test } \\
X^{2}=4.97 p=.083\end{array}$ \\
\hline \multirow{4}{*}{ C2 } & $\begin{array}{c}\text { Ownership } \\
\text { Likert } \alpha=.73\end{array}$ & No difference & $\begin{array}{l}\text { Gesture } \mathrm{m}=2.31, \mathrm{SD}=.78 \\
\text { Sketch } \mathrm{m}=2.53, \mathrm{SD}=.82\end{array}$ & $\begin{array}{c}\text { Mann-Whitney U test (2-tail) } \\
\qquad U=696 p=.278\end{array}$ \\
\hline & $\begin{array}{c}\text { Attachment } \\
\text { Likert } \alpha=.70\end{array}$ & No difference & $\begin{array}{l}\text { Gesture } m=1.70, S D=.44 \\
\text { Sketch } m=1.94, S D=.53\end{array}$ & $\begin{array}{l}\text { Mann-Whitney U test (2-tail) } \\
\qquad \mathrm{U}=758 p=.069\end{array}$ \\
\hline & $\begin{array}{l}\text { Self-extension } \\
\text { Likert } \alpha=.65\end{array}$ & No difference & $\begin{array}{l}\text { Gesture } m=2.19, S D=.77 \\
\text { Sketch } m=2.43, S D=.76\end{array}$ & 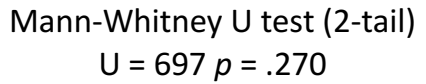 \\
\hline & $\begin{array}{c}\text { Satisfaction } \\
\text { Likert } \alpha=.76\end{array}$ & No difference & $\begin{array}{l}\text { Gesture } m=2.77, S D=.71 \\
\text { Sketch } m=2.81, S D=.69\end{array}$ & $\begin{array}{l}\text { Mann-Whitney U test (2-tail) } \\
\qquad \begin{array}{c}\text { U } \\
\text { (23 } p=.826\end{array}\end{array}$ \\
\hline \multirow{2}{*}{ C3 } & $\begin{array}{l}\text { Proportion of own } \\
\text { ideas selected }\end{array}$ & No difference & $\begin{array}{l}\text { Gesture } \mathrm{m}=.55, \mathrm{SD}=.20 \\
\text { Sketch } \mathrm{m}=.58, \mathrm{SD}=.21\end{array}$ & $\begin{array}{c}\text { t-test (2-tail) } \\
p=.609\end{array}$ \\
\hline & $\begin{array}{l}\text { Replication of Toh et } \\
\text { al. (2015) gender bias }\end{array}$ & $\begin{array}{l}\text { No difference } \\
\mathrm{N}=38 \mathrm{~F} / 49 \mathrm{M}\end{array}$ & $\begin{array}{c}\text { Female } m=.57, S D=.18 \\
\text { Male } m=.58, S D=.20\end{array}$ & $\begin{array}{l}\text { t-test (2-tail) } \\
\quad p=.815\end{array}$ \\
\hline
\end{tabular}

\section{$5 \quad$ Testing a general account of design representation}

Based on the results and building on recent developments in cognitive psychology (Evans \& Stanovich, 2013), we conceptualise the impact of design representation based on interaction between Type 1 and Type 2 processing driven by match between input/response, and interplay between implicit modal and explicit information content. By examining sketching and gesture across a range of common design tasks, including reproduction, evaluation, elaboration, ideation, and selection, we test an array of predictions derived from dual-process theory. This offers multiple windows into the implications of dual-process theory across the design process.

Collectively, the results support an understanding of design work based on an interplay between Type 1 and Type 2 processing, jointly shaping design outcomes. This aligns with prior work in the creativity literature (Sowden et al., 2015) as well as more general discussions of potential dual-process explanations of design (Badke-Schaub \& Eris, 2014). First, match between input and response impacts almost all aspects of design work across a range of measures. For example, with matched input/response leading to easier reproduction and more elaboration but lower development and originally. This highlights the importance of match between input/response both in terms of its potential impact on design work but also when interpreting design studies with multiple input representation modes being contrasted based on results derived from only one representation mode. This methodological implication could help explain some of the varied results when comparing prior design studies contrasting multiple stimuli in matched and mismatched conditions (Linsey et al., 2011; Toh \& Miller, 2014). Second, our results highlight the need to differentiate explicit and implicit information and how these interact with the design task, which aligns with similar distinctions found in studies of uncertainty (Cash \& Kreye, 2018; Sloman, 2002). This could help explain the observed differences in fluency and novelty results in, for example, the fixation literature (Sio et al., 2015; Vasconcelos \& Crilly, 
2016). Finally, our results highlight the limitations of operationalising and testing abstract cognitive theory in the design context and the significant theory development still needed in order to translate dual-process mechanisms into design relevant measures.

This research addresses the need for theoretical synthesis by describing common mechanisms through which design representation can be understood across design tasks. Further, this work provides an important empirical contribution by adding to the previously limited set of comparative studies in the design representation context (Maier \& Kleinsmann, 2013; Toh \& Miller, 2014; Visser \& Maher, 2011). More generally, this work helps demonstrate the potential for the adaption of theory from other fields into the design domain based on the principals of theory-driven design research (Cash, 2018, 2020). Together these substantially extend prior research on design representation, in particular sketching and gesture, and provide the basis for a number of implications for design theory, education, and practice.

In summary, this work provides a basis for three main extensions to design theory. First, we take a step towards explaining how interactions between Type 1 and Type 2 processing can be used to understand designers' differing responses to, and usage of, varied representation types. Second, we complement the growing body of work on dual-process related creativity, by linking variation in match between input/response to creative outcomes across the design process. Finally, we point to the need to understand the potentially differing impact of explicit and implicit information content in design tasks and other stimuli.

\subsection{Limitations}

Before discussing the implications there are two main limitations to be considered. First, while dual-process theory is relatively mature (Evans, 2008), its application to design is very limited (Badke-Schaub \& Eris, 2014; Cash, Daalhuizen, et al., 2019), and questions remain about its exact mechanisms. This means that there are a number of questions requiring further study regarding how exactly to operationalise dual-process hypotheses and measures relevant to design research. Further, mechanisms dealing with the distribution and interaction between Type 1 and Type 2 processing during tasks are yet to be fully understood. As such, we have focused on developing hypotheses connected to design relevant measures and concrete accounts of design work (Table 2). The limitation of this approach is that we have encountered a number of null results (Tables 3 and 4), which, while explainable, are not easily disentangled within the current research framework. Further, it means we do not provide direct evidence for specific processing types, but rather build on the postulated mechanisms to explain design-relevant measures. In particular, permutations of input and response could be evaluated to further interrogate the hypothesised mechanisms regarding match/mismatch and associated mental simulation demands. Future studies could manipulate the explicit content and examine how it is interpreted and manipulated by the designer in various conditions. Thus, further theory-development is needed in order to operationalise dual-process concepts and measures into a design relevant framework, able to disambiguate the multiple mechanisms and effects at play. 
Second, while the reported studies (Table 1) follow typical best practice in terms of study design and sample size in design research, further empirical work is needed in two dimensions: i) expansion of the quantitative sample via replication as well as experimentation elaborating on the results in this work; ii) development of complementary qualitative work to explore the degree to which experimental insights translate to design in practice. Both of these dimensions require a wider programme of research related by common theory, as highlighted in recent discussions by Ball and Christensen (Ball \& Christensen, 2018; Christensen \& Ball, 2019) and Cash $(2018,2020)$. Thus, while the current work has a number of limitations, it nerveless provides a clear foundation for future development of dual-process theory in the design context.

\subsection{Implications for design theory}

First, this work demonstrates how an interplay between intuitive Type 1 and reflective Type 2 processing can explain a number of design representation results across a range of design tasks. By testing specific predictions, we substantially extend the debate regarding the potential applicability of dual-process theory in the design context (Badke-Schaub \& Eris, 2014; Cash, Daalhuizen, et al., 2019; Crilly \& Cardoso, 2017), and provide another example of dual-process theory's predictive power in practice (Evans \& Stanovich, 2013). We highlight the interaction between Type 1 and Type 2 processing as a potential explanation linking previously distinct bodies of research in design (Ball \& Christensen, 2009; Mulder, Swaak, \& Kessels, 2004). In order to further extend and elaborate understanding regarding these potential links, future work could systematically compare applications of dual-process theory in design research, for example to intuition and decision making (Badke-Schaub \& Eris, 2014), creativity (Sowden et al., 2015), and method use (Daalhuizen, 2014). In addition, further work is needed to elaborate the complex interactions between dual-processing mechanisms and the contextually situated factors that also influence design work in practice (Ball \& Christensen, 2018; Hay et al., 2017).

Second, this work expands the scope of prior applications of dual-process theory in design research to representation, which, to-date, has been little studied through this lens (Eris et al., 2014; Scaife \& Rogers, 1996; Visser \& Maher, 2011). Importantly, because dual-process theory describes abstract cognitive mechanisms it has the potential to extend predictions to new or emerging design contexts, as well as new or emerging representation modes in design, such as AR, VR (Ng, Oon, Ong, \& Nee, 2011) or tangible interfaces (Oppl \& Stary, 2013). Thus, this work forms a basis for possible elaboration of dual-process theory in the wider design representation context. Future work could expand the scope of operationalisation by testing predictions across emerging representation modes, such as AR or VR, as well as other contexts, such as multimodal teamwork in practice (Cash, Skec, \& Storga, 2019; Dong, Kleinsmann, \& Deken, 2013). Further, by providing a formal model linking representation inputs and responses across design tasks this study could also inform future development of agent based models of designers and design teams, which have already shown promising steps towards incorporating dual-processing mechanisms to explain design work (Perisic, 
Martinec, Storga, \& Gero, 2019; Perisic, Storga, \& Gero, 2019; Sosa, 2016). Collectively, these point to a number of research directions that link to recent work, e.g. by Hay et al. (2020).

\subsection{Implications for design education and practice}

Our findings also have implications for both educational and professional settings. Specifically, we highlight two mechanisms that can inform the use of representation, during, for example, instruction or training in education and design reviews or handovers in practice. First, when input and desired response are mismatched there is an apparent reduction in repetition and increase in interpretation and development. For example, we observed how a matched condition with sketched input/response supported more complete and accurate reproduction of a communicated concept, at the cost of also allowing for uncritical copying. Second, the implicit modal information of a representation prompts associations that parallel interpretation of explicit information content. For example, we observed how gestured inputs prompted a focus on spatial and dynamic features without necessarily compromising a designer's ability to evaluate the concept being represented. Further, while both modes of representation proved effective prompts for elaboration and ideation, gesture favoured a focus on spatial and dynamic features while sketching drew attention to structural features. As such, designers and design educators should deliberately select the input and response mode of representation that best fit their design task. These results could also expand the scope of recommendations for the development of representational communication and design tools (Kulkarni et al., 2000) as well as specific design education (Booth et al., 2016). Further work is needed to examine other task relevant impacts of mode of representation, such as long-term recall (Stark \& Perfect, 2008) or persuasiveness (Babapour, 2016; Pei et al., 2011).

\section{$6 \quad$ Conclusions}

The aim of this study was to provide a more general account of design representation by operationalising and testing predictions from dual-process theory with respect to the differing impacts of gesture and sketching across design tasks. We show that similarities and differences between gesture and sketching in design can be predicted using dual-process theory. Based on these results, the impact of design representation is conceptualised in terms of an interaction between Type 1 and Type 2 processing. Our findings lead to three main contributions. First, we demonstrate how dual-process theory can explain key design representation results across design tasks, including reproduction, evaluation, elaboration, ideation, and selection. Second, by operationalising dual-process theory in this context we provide a foundation for developing a more general account of design representation. Finally, we highlight specific strengths and weaknesses of different input/response combinations of sketching and gesture across design tasks in order to provide practical guidance for design educators and practitioners. These contributions extend prior research on design representation and add to discussions of design cognition and communication, design theory, and the use of design representation in education and practice. 
Looking forward, this paper also contributes to the emerging dialogue on design in the age of data, digitalisation, and Artificial Intelligence (Al). In particular, our findings have implications for understanding multi-modality, and the interplay between representation modes, especially gesture and sketching in XR. Given the fast pace of advances in Al, cognition support, and automated design tools and learning algorithms, general accounts of design are critical to understanding and supporting new forms of design work. Thus, we hope this work serves to spark debate regarding how working with theory can inform the wider impact of design research.

\section{Acknowledgement}

The authors would like to thank the reviewers and editors for helping to substantially develop this manuscript.

\section{References}

Akinci, C., \& Sadler-Smith, E. (2019). Collective Intuition: Implications for Improved Decision Making and Organizational Learning. British Journal of Management, 30(3), 558-577.

Babapour, M. (2016). Roles of externalisation activities in the design process. Swedish Design Research Journal, 11(1), 34.

Badke-Schaub, P., \& Eris, O. (2014). A Theoretical Approach to Intuition in Design: Does Design Methodology Need to Account for Unconscious Processes? In A. Chakrabarti \& L. T. M. Blessing (Eds.), An Anthology of Theories and Models of Design: Philosophy, Approaches and Empirical Explorations (pp. 353-370). London: Springer London.

Ball, L. J., \& Christensen, B. T. (2009). Analogical reasoning and mental simulation in design: two strategies linked to uncertainty resolution. Design Studies, 30(2), 169-186.

Ball, L. J., \& Christensen, B. T. (2018). Designing in the wild. Design Studies, 57(1995), 1-8.

Ball, L. J., \& Christensen, B. T. (2019). Advancing an understanding of design cognition and design metacognition: progress and prospects. Design Studies, 65, IN PRESS.

Baskinger, M., \& Nam, K.-C. (2006). Visual narratives: The essential role of imagination in the visualization process. In Conferences in Research and Practice in Information Technology Series (pp. 217-220).

Beaty, R. E., Kenett, Y. N., Christensen, A. P., Rosenberg, M. D., Benedek, M., Chen, Q., ... Silvia, P. J. (2018). Robust prediction of individual creative ability from brain functional connectivity. Proceedings of the National Academy of Sciences of the United States of America, 115(5), 1087-1092.

Becvar, A., Hollan, J., \& Hutchins, E. (2008). Representational gestures as cognitive artifacts for developing theories in a scientifc laboratory. In M. S. Ackerman, C. A. Halverson, T. Erickson, \& W. A. Kellogg (Eds.), Resources, Co-Evolution and Artifacts (pp. 117-143). Springer.

Bekker, M. M., Olson, J. S., \& Olson, G. M. (1995). Analysis of gestures in face-to-face design teams provides guidance for how to use groupware in design. In DIS '95 Proceedings of the 1st conference on Designing interactive systems: processes, practices, methods, \& techniques (pp. 157-166). New York, US: ACM.

Bello, D., Leung, K., Radebaugh, L., Tung, R. L., \& Van Witteloostuijn, A. (2009). From the Editors: Student samples in international business research. Journal of International Business Studies, 40(3), 361-364.

Bilda, Z., \& Demirkan, H. (2003). An insight on designers' sketching activities in traditional versus digital media. Design Studies, 24(1), 27-50.

Bilda, Z., Gero, J. S., \& Purcell, T. (2006). To sketch or not to sketch? That is the question. Design Studies, 27(5), 587-613.

Booth, J. W., Taborda, E. A., Ramani, K., \& Reid, T. (2016). Interventions for teaching sketching skills and reducing inhibition for novice engineering designers. Design Studies, 43, 1-23.

Buchem, I. (2012). Psychological Ownership and Personal Learning Environments: Do sense of ownership and control really matter? In The third PLE conference (p. 21). Aveiro, Portugal.

Cash, P. (2018). Developing theory-driven design research. Design Studies, 56(May), 84-119. 
Cash, P. (2020). Where next for design research? Understanding research impact and theory building. Design Studies, 68, 113-141.

Cash, P., \& Culley, S. (2014). The Role of Experimental Studies in Design Research. In P. Rodgers \& J. Yee (Eds.), The Routledge Companion to Design Research (pp. 175-189). New York, NY, USA: Routledge.

Cash, P., Daalhuizen, J., Valgeirsdottir, D., \& Van Oorschot, R. (2019). A Theory-Driven Design Research Agenda: Exploring Dual-Process Theory. In ICED 19 International Conference on Engineering Design (pp. 1373-1382).

Cash, P., Hicks, B. J., \& Culley, S. J. (2013). A comparison of designer activity using core design situations in the laboratory and practice. Design Studies, 34(5), 575-611.

Cash, P., \& Kreye, M. E. (2017). Uncertainty Driven Action (UDA) model: A foundation for unifying perspectives on design activity. Design Science, 3(e26), 1-41.

Cash, P., \& Kreye, M. E. (2018). Exploring Uncertainty Perception as a Driver of Design Activity. Design Studies, 54(January), 50-79.

Cash, P., \& Maier, A. (2016). Prototyping with your hands: the many roles of gesture in the communication of design concepts. Journal of Engineering Design, 27(1-3), 118-145.

Cash, P., Skec, S., \& Storga, M. (2019). The dynamics of design: Exploring heterogeneity in meso-scale team processes. Design Studies, 64(September), 124-153.

Christensen, B. T., \& Ball, L. J. (2019). Building a Discipline: Indicators of expansion, integration and consolidation in design research across four decades. Design Studies, 65, 18-34.

Chu, M., \& Kita, S. (2011). The nature of gestures' beneficial role in spatial problem solving. Journal of Experimental Psychology. General, 140(1), 102-16.

Crilly, N., \& Cardoso, C. (2017). Where next for research on fixation, inspiration and creativity in design? Findings from an international workshop. Design Studies, 50, 1-38.

Cross, N. (2008). Engineering design methods: strategies for product design. Wiley and Sons, Inc.

Daalhuizen, J. (2014). Method Usage in Design: How methods function as mental tools for designers. Delft University of Technology.

Dane, E., \& Pratt, M. G. (2007). Exploring intuition and its role in managerial decision making. Academy of Management Review, 32(1), 33-54.

Davis, B. (2016). Gesture, Creativity and Design. In ICDC2016: The 4th International Conference on Design Creativity (pp. 1-13). Atlanta, GA, USA.

Dong, A., Kleinsmann, M., \& Deken, F. (2013). Investigating design cognition in the construction and enactment of team mental models. Design Studies, 34(1), 1-33.

Eris, O., Martelaro, N., \& Badke-Schaub, P. (2014). A comparative analysis of multimodal communication during design sketching in co-located and distributed environments. Design Studies, 35(6), 559-592.

Evans, J. S. B. T. (2008). Dual-processing accounts of reasoning, judgment, and social cognition. Annual Review of Psychology, 59, 255-278.

Evans, J. S. B. T., \& Stanovich, K. E. (2013). Dual-process Theories of Higher Cognition: Advancing the Debate. Perspectives on Psychological Science, 8(3), 223-241.

Furlan, S., Agnoli, F., \& Reyna, V. F. (2016). Intuition and analytic processes in probabilistic reasoning: The role of time pressure. Learning and Individual Differences, 45, 1-10.

Garber, P., \& Goldin-Meadow, S. (2002). Gesture offers insight into problem-solving in adults and children. Cognitive Science, 26(6), 817-831.

Goldin-Meadow, S. (1999). The role of gesture in communication and thinking. Trends in Cognitive Sciences, $3(11), 419-429$.

Goldschmidt, G. (2007). To see eye to eye: the role of visual representations in building shared mental models in design teams. CoDesign, 3(1), 43-50.

Gonçalves, M., Cardoso, C., \& Badke-Schaub, P. (2016). Inspiration choices that matter: the selection of external stimuli during ideation. Design Science, 2(November), e10.

Harkki, T., Seitamaa-Hakkarainen, P., \& Hakkarainen, K. (2018). Hands on design: comparing the use of sketching and gesturing in collaborative designing. Journal of Design Research, 16(1), 24-46.

Hay, L., Cash, P., \& McKilligan, S. (2020). The future of design cognition analysis. Design Science, 6(20), 1-26.

Hay, L., Duffy, A., McTeague, C., Pidgeon, L., Vuletic, T., \& Grealy, M. (2017). A systematic review of protocol studies on conceptual design cognition: Design as search and exploration. Design Science, 3(Visser 2004), e10. 
Hegarty, M. (2004). Mechanical reasoning by mental simulation. Trends in Cognitive Sciences, 8(6), 280-285. Hoegg, J., \& Alba, J. W. (2011). Seeing is believing (too much): The influence of product form on perceptions of functional performance. Journal of Product Innovation Management, 28(3), 346-359.

Howard-Jones, P. A. (2002). A dual-state model of creative cognition for supporting strategies that foster creativity in the classroom. International Journal of Technology and Design Education, 12(3), 215-226.

Jonson, B. (2005). Design ideation: the conceptual sketch in the digital age. Design Studies, 26(6), 613-624.

Kannengiesser, U., \& Gero, J. S. (2019). Design thinking, fast and slow: A framework for Kahneman's dualsystem theory in design. Design Science, 5, 1-21.

Kavakli, M., \& Gero, J. S. (2001). Sketching as mental imagery processing. Design Studies, 22(4), 347-364.

Kelly, N., \& Gero, J. S. (2014). Interpretation in design: Modelling how the situation changes during design activity. Research in Engineering Design, 25(2), 109-124.

Kirk, R. E. (2009). Experimental design. London, UK: Sage Publications.

Kleinmintz, O. M., Ivancovsky, T., \& Shamay-Tsoory, S. G. (2019). The two-fold model of creativity: the neural underpinnings of the generation and evaluation of creative ideas. Current Opinion in Behavioral Sciences, 27, 131-138.

Kudrowitz, B., Te, P., \& Wallace, D. (2012). The influence of sketch quality on perception of product-idea creativity. Artificial Intelligence for Engineering Design, Analysis and Manufacturing: AIEDAM, 26(3), 267-279.

Kulkarni, S., Summers, J. D., Vargas-Hernandez, N., \& Shah, J. J. (2000). Evaluation of Collaborative Sketching (C-Sketch) as an Idea Generation Technique for Engineering Design. Journal of Creative Behaviour, 35(3), 168-198.

Linsey, J. S., Clauss, E. F., Kurtoglu, T., Murphy, J. T., Wood, K. L., \& Markman, a B. (2011). An Experimental Study of Group Idea Generation Techniques: Understanding the Roles of Idea Representation and Viewing Methods. Journal of Mechanical Design, 133(3), 1-15.

Luck, R. (2010). Using objects to coordinate design activity in interaction. Construction Management and Economics, 28(6), 641-655.

Luck, R. (2014). Seeing architecture in action: designing, evoking, and depicting space and form in embodied interaction. International Journal of Design Creativity and Innovation, 2(3), 165-181.

Maier, A. M., \& Kleinsmann, M. (2013). Studying and supporting design communication. Artificial Intelligence for Engineering Design, Analysis and Manufacturing, 27(2), 87-90.

Mayer, R. E., \& Moreno, R. (2003). Nine ways to reduce cognitive load in multimedia learning. Educational Psychologist, 38(1), 43-52.

McAlpine, H., Cash, P., \& Hicks, B. (2017). The role of logbooks as mediators of engineering design work. Design Studies, 48(January), 1-29.

Menezes, A., \& Lawson, B. (2006). How designers perceive sketches. Design Studies, 27(5), 571-585.

Miles, M. B., \& Huberman, A. M. (1994). Qualitative data analysis: An expanded sourcebook. Thousand Oaks, California: Sage.

Mueller, J. S., Melwani, S., \& Goncalo, J. A. (2012). The bias against creativity: Why people desire but reject creative ideas. Psychological Science, 23(1), 13-17.

Mulder, I., Swaak, J., \& Kessels, J. (2004). In search of reflective behavior and shared understanding in ad hoc expert teams. Cyberpsychology \& Behavior, 7(2), 141-54.

Murphy, K. M. (2005). Collaborative imagining: The interactive use of gestures, talk, and graphic representation in architectural practice. Semiotica, 2005(156), 113-145.

Ng, L. X., Oon, S. W., Ong, S. K., \& Nee, A. Y. C. (2011). GARDE: A gesture-based augmented reality design evaluation system. International Journal on Interactive Design and Manufacturing, 5(2), 85-94.

Norman, G. R., Monteiro, S. D., Sherbino, J., Ilgen, J. S., Schmidt, H. G., \& Mamede, S. (2017). The Causes of Errors in Clinical Reasoning: Cognitive Biases, Knowledge Deficits, and Dual Process Thinking. Academic Medicine, 92(1), 23-30.

Oliver, R. L. (1980). A cognitive model of the antecedents and consequences of satisfaction decisions. Journal of Marketing Research, 17(4), 460-469.

Onwuegbuzie, A. J., \& Collins, K. M. T. (2007). A Typology of Mixed Methods Sampling Designs in Social Science Research. The Qualitative Report, 12(2), 281-316.

Oppl, S., \& Stary, C. (2013). Facilitating shared understanding of work situations using a tangible tabletop interface. Behaviour \& Information Technology, 33(6), 619-635. 
Oxman, R. (1997). Design by re-representation: a model of visual reasoning in design. Design Studies, 18(4), 329-347.

Pei, E., Campbell, R. I., \& Evans, M. A. (2011). A Taxonomic classification of visual design representations used by industrial designers. The Design Journal, 14(1), 64-91.

Perisic, M. M., Martinec, T., Storga, M., \& Gero, J. S. (2019). A Computational Study of the Effect of Experience on Problem/Solution Space Exploration in Teams. In Proceedings of the Design Society: International Conference on Engineering Design (pp. 11-20).

Perisic, M. M., Storga, M., \& Gero, J. S. (2019). Situated Novelty in Computational Creativity Studies. In 10th International Conference on Computational Creativity ICCC19.

Rietzschel, E. F., Nijstad, B. A., \& Stroebe, W. (2010). The selection of creative ideas after individual idea generation: Choosing between creativity and impact. British Journal of Psychology, 101(1), 47-68.

Roth, W.-M. (2001). Gestures: Their Role in Teaching and Learning. Review of Educational Research, 71(3), 365-392.

Scaife, M., \& Rogers, Y. (1996). External cognition: how do graphical representations work? International Journal of Human-Computer Studies, 45(2), 185-213.

Schifferstein, H. N. J., \& Zwartkruis-Pelgrim, E. P. H. (2008). Consumer-product attachment: Measurement and design implications. International Journal of Design, 2(3), 1-13.

Scrivener, S. A. R., Ball, L. J., \& Tseng, W. (2000). Uncertainty and sketching behaviour. Design Studies, 21(5), 465-481.

Sevier, D. C., Jablokow, K., McKilligan, S., Daly, S. R., Baker, I. N., \& Silk, E. M. (2017). Towards the development of an elaboration metric for concept sketches. In Proceedings of the ASME Design Engineering Technical Conference (pp. 1-10).

Shah, J. J., Smith, S. M., \& Vargas-Hernandez, N. (2003). Metrics for measuring ideation effectiveness. Design Studies, 24(2), 111-134.

Sio, U. N., Kotovsky, K., \& Cagan, J. (2015). Fixation or inspiration? A meta-analytic review of the role of examples on design processes. Design Studies, 39, 70-99.

Sloman, S. A. (2002). Two systems of reasoning. In T. Gilovich, D. Griffin, \& D. Kahneman (Eds.), Heuristics and Biases: The Psychology of Intuitive Thought (pp. 397-420). New York, NY, US: Cambridge University Press.

Sosa, R. (2016). Computational Modelling of Teamwork in Design. In P. Cash, T. Stankovic, \& M. Storga (Eds.), Experimental Design Research: Approaches, perspectives, applications (pp. 173-186). Springer.

Sowden, P. T., Pringle, A., \& Gabora, L. (2015). The Shifting Sands of Creative Thinking: Connections to Dual Process Theory. Thinking \& Reasoning, 21(1), 40-60.

Stacey, M., Eckert, C., \& McFadzean, J. (1999). Sketch Interpretation in Design Communication. In ICED 09 International Conference on Engineering Design (pp. 1-6).

Stanovich, K. E. (2009). Distinguishing the reflective, algorithmic, and autonomous minds: Is it time for a triprocess theory? In In Two Minds: Dual Processes and Beyond (pp. 55-88).

Stanovich, K. E., Toplak, M. E., \& West, R. F. (2008). The development of rational thought: A taxonomy of heuristics and biases. Advances in Child Development and Behavior (Vol. 36). Elsevier B.V.

Stanovich, K. E., West, R. F., \& Toplak, M. E. (2012). Intelligence and rationality. In R. Sternberg \& S. B. Kaufman (Eds.), Cambridge handbook of intelligence (3rd Edition) (pp. 784-826). Cambridge UK: Cambridge University Press.

Stark, L. J., \& Perfect, T. J. (2007). Whose idea was that? Source monitoring for idea ownership following elaboration. Memory, 15(7), 776-783.

Stark, L. J., \& Perfect, T. J. (2008). The effects of repeated idea elaboration on unconscious plagiarism. Memory and Cognition, 36(1), 65-73.

Starkey, E., Toh, C. A., \& Miller, S. R. (2016). Abandoning creativity: The evolution of creative ideas in engineering design course projects. Design Studies, 47, 47-72.

Steinert, M., \& Leifer, L. (2011). "Finding One's Way": Re-Discovering a Hunter- Gatherer Model based on Wayfaring. International Journal of Engineering Education, 28(2), 251-252.

Steur, R. (2019). Sketching: Drawing Techniques for Product Designers. Amsterdam, The Netherlands: BIS Publishers BV.

Sun, G., \& Yao, S. (2012). Investigating the relation between cognitive load and creativity in the conceptual design process. In PROCEEDINGS of the HUMAN FACTORS and ERGONOMICS SOCIETY 56th ANNUAL 
MEETING (pp. 308-312).

Suwa, M., \& Tversky, B. (1997). What do architects and students perceive in their design sketches? A protocol analysis. Design Studies, 18(4), 385-403.

Thoma, V., White, E., Panigrahi, A., Strowger, V., \& Anderson, I. (2015). Good thinking or gut feeling? Cognitive reflection and intuition in traders, bankers and financial non-experts. PLOS ONE, 10(4), 1-17.

Toh, C. A., Miele, L. M., \& Miller, S. R. (2015). Which one should I pick? Concept selection in engineering design industry. In Proceedings of the ASME Design Engineering Technical Conference (Vol. 7, pp. 1-10).

Toh, C. A., \& Miller, S. R. (2014). The impact of example modality and physical interactions on design creativity. Journal of Mechanical Design, Transactions of the ASME, 136(9), 1-8.

Toh, C. A., \& Miller, S. R. (2015). How engineering teams select design concepts: A view through the lens of creativity. Design Studies, 38(C), 111-138.

Toh, C. A., Strohmetz, A. A., Patel, A. H., \& Miller, S. R. (2015). MY IDEA IS BEST ! OWNERSHIP BIAS AND ITS INFLUENCE ON ENGINEERING. In DETC '15: ASME 2015 Design Engineering Technical Conferences (pp. 1-10).

Tversky, B. (2011). Visualizing thought. Topics in Cognitive Science, 3(3), 499-535.

Valkenburg, R., \& Dorst, K. (1998). The reflective practice of design teams. Design Studies, 19(3), 249-271.

Van Der Lugt, R. (2005). How sketching can affect the idea generation process in design group meetings. Design Studies, 26(2), 101-112.

Vasconcelos, L. A., Cardoso, C. C., Sääksjärvi, M., Chen, C.-C., \& Crilly, N. (2017). Inspiration and Fixation: The Influences of Example Designs and System Properties in Idea Generation. Journal of Mechanical Design, Transactions of the ASME, 139(3), 1-13.

Vasconcelos, L. A., \& Crilly, N. (2016). Inspiration and fixation: Questions, methods, findings, and challenges. Design Studies, 42(C), 1-32.

Visser, W., \& Maher, M. L. (2011). The role of gesture in designing. Guest editorial. Al EDAM (Artificial Intelligence for Engineering Design, Analysis and Manufacturing), 25(3), 213-220.

Wacker, J. G. (2008). A conceptual understanding of requirements for theory-building research: Guidelines for scientific theory building. Journal of Supply Chain Management, 44(3), 5-15.

Waldherr, S., Romero, R., \& Thrun, S. (2000). A gesture based interface for human-robot interaction. Autonomous Robots, 9(2), 151-173.

Wilson, M. (2002). Six views of embodied cognition. Psychonomic Bulletin \& Review, 9(4), 625-636.

Wiltschnig, S., Christensen, B. T., \& Ball, L. J. (2013). Collaborative problem-solution co-evolution in creative design. Design Studies, 34(5), 515-542.

Yang, M. C. (2005). A study of prototypes, design activity, and design outcome. Design Studies, 26(6), 649669.

Yang, M. C. (2009). Observations on concept generation and sketching in engineering design. Research in Engineering Design, 20(1), 1-11. 